\title{
Community-Driven Knowledge Organization for Cultural Heritage Digital Libraries: The Case of the Inuvialuit Settlement Region
}

\author{
Sharon Farnel \\ University of Alberta \\ sharon.farnel@ualberta.ca
}

\author{
Ali Shiri \\ University of Alberta \\ ali.shiri@ualberta.ca
}

\begin{abstract}
The Inuvialuit Digital Library (https://inuvialuitdigitallibrary.ca/) was developed as part of the Digital Library North Project, a four-year collaboration to develop a digital library infrastructure to support preservation of and access to cultural resources in the Inuvialuit Settlement Region in north western Canada. In this paper, we present the methodologies and approaches used in the development of a culturally appropriate metadata and description framework for the digital library. Specifically, we address soliciting community involvement for building knowledge organization systems, culturally appropriate feedback mechanisms for correcting knowledge organization practices, and deciding who will create the structure and format of knowledge organization systems. Specific practical considerations and decisions on culturally appropriate metadata elements are discussed, in particular such description and design elements as subjects, contributors and roles, language and dialects, geographic names and user interface functionalities.
\end{abstract}

\section{Keywords}

Knowledge organization, Inuvialuit, Digital libraries, Community-driven research, Metadata.

\section{INTRODUCTION}

The Inuvialuit Digital Library (IDL) was developed as part of the Digital Library North Project (DLN), a four-year collaboration between researchers at the University of Alberta, staff at the Inuvialuit Cultural Centre (ICC), and communities within the Inuvialuit Settlement Region (ISR), to develop a digital library infrastructure to support access to cultural resources (Shiri \& Rathi, 2015; Digital Library North, 2017). The Library (https://inuvialuitdigitallibrary.ca/), which is built using the Omeka open-source web publishing platform (https://omeka.org/), currently consists of more than 5,200 digital resources of four different types - audio, video, images, and texts - organized into 49 different collections. All items have at minimum a title and type which is added upon ingest. Most other resources have had richer metadata descriptions added, and this work is ongoing.

$81^{\text {st }}$ Annual Meeting of the Association for Information Science \& Technology | Vancouver, Canada | Nov. 10 - 14, 2018

Author(s) Retain Copyright
The Inuvialuit Settlement Region (ISR) was designated in 1984 in the Inuvialuit Final Agreement between the Government of Canada and the Inuvialuit. There are six communities within the ISR: Aklavik, Inuvik, Paulatuk, Sachs Harbour, Tuktoyaktuk, and Ulukhaktok. The population of the region is approximately 6,500 , with more than half $(3,400)$ based in Inuvik, the regional centre. The Indigenous language of the Inuvialuit is Inuvialuktun, which is comprised of three dialects: Kangiryuarmiutun, Siglitun, and Uummarmiutun. English is also spoken throughout the region (Inuvialuit Regional Corporation, 2017). The Inuvialuit Cultural Centre (ICC), a division of the Inuvialuit Regional Corporation (IRC), was founded in 1998 with a mandate to promote and preserve the language and culture of the Inuvialuit of northern Canada (Inuvialuit Cultural Centre, 2017).

In this paper, we will present the methodologies and approaches used in the development of a culturally appropriate metadata and description framework for a digital library developed for Inuit communities in Canada's North. Specifically, we address the key issues outlined in the Workshop call for proposals, namely soliciting community involvement for building knowledge organization systems, culturally appropriate feedback mechanisms for correcting knowledge organization practices, and deciding who will create the structure and format of knowledge organization systems. Specific practical considerations and decisions on culturally appropriate metadata elements will be discussed.

\section{METHODOLOGIES AND METHODS}

The DLN Project was both community-focused and community-driven, and its work was therefore informed by both Indigenous and participatory paradigms. An Indigenous paradigm is grounded in Indigenous knowledge and Indigenous ways of knowing. It requires an appreciation and respect for relationships, an understanding of knowledge as communal and interconnected, individuals as situated, and respectful and ethical engagement (Chilisa, 2012; Hart, 2010; Kovach, 2005, 2010; Lavallée, 2009; Wilson, 2008). Participatory research emphasizes culture-based creation of knowledge and entails equal and cooperative exchange of local cultural knowledge and academic knowledge to drive inquiry (Balanoff, Kudlak, Kaodloak, and Chambers, 2006; Baydala, Placsko, Hampton, Bourassa, \& McKay-McNabb, 2006; Lincoln, Lynham, \& Guba, 2011). It aims to improve a given social reality through insights gained from reciprocal knowledge exchange, integrates theory and practice, and 
strives for community capacity building. The Project employed culturally appropriate methods including interviews and focus groups, open houses, informal conversations, and participant observation (Bushnell, 2009; Hollowell, 2009; Walts, 2011).

\section{Community Engagement}

We made use of a variety of methods and data gathering techniques (see Figure 1) that were suitable for the Inuvialuit cultural and linguistic context. The project was driven by a broad range of individuals and community organizations, including community leaders, elders and members who were closely involved in the shaping and development of the Inuvialuit Digital Library. The choice of content, the representation of that content in the Digital Library, and the design of the user interface were all determined in close and ongoing consultation with community members, in particular, students, language instructors, staff at the ICC, archivists and librarians, and researchers.

Past and current managers and staff of the ICC are critical project collaborators. They are community members and trusted curators of the valuable cultural and linguistic resources that are found in the library. Their strong sense of the potential roles for the Digital Library drives the project. Not to be overlooked is the ongoing support of the IRC leadership, in particular those involved with culture, language, and research, which has been a key component of the success of the project to date. Community input has been gained through more formal means including interviews and user testing sessions (15) as well as surveys (68). Less formal input and feedback has been gained through demonstrations at the Inuvik high school (3), information tables at community events and locations (6), open houses (6), which include demonstrations, informal conversations, and participant observation, in five of the six ISR communities. Team members make regular trips to the community. These trips range in length from one week to several months, and take place at different times of the year.

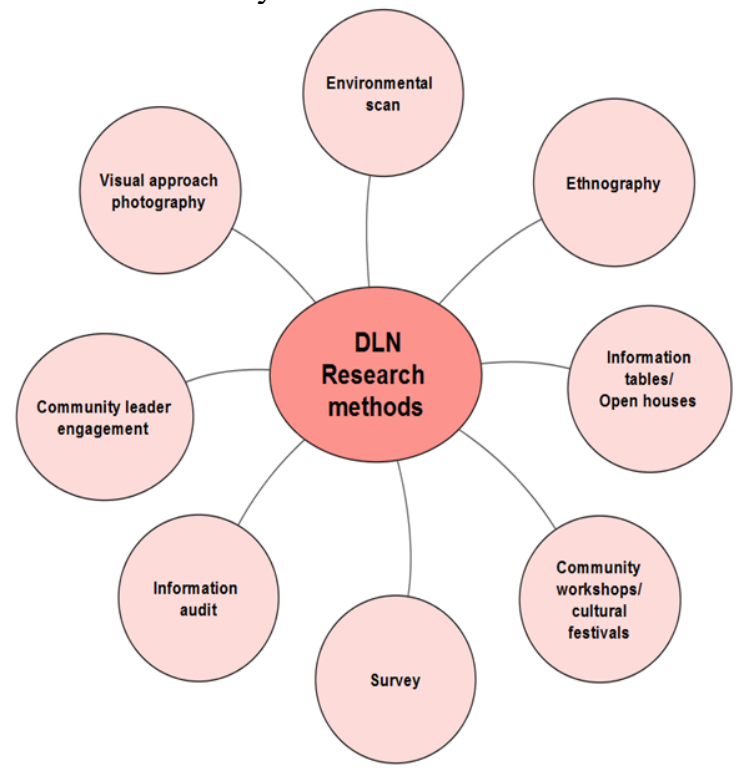

Figure 1. Diversity of Methodologies \& Theoretical Frameworks

\section{BUILDING THE METADATA FRAMEWORK}

\section{Structure}

From the earliest conversations, community members emphasized the importance of a browse interface for the content in the Library. For this reason, the Library allows users to browse by Collection (see Figure 2). The top level divides collections by type: Audio, Video, Text, and Language Resources. Each of these is then further divided into sub-collections, such as oral history recordings or book collections. There is also a top level browse by Type, which allows users to immediately gain access to all items of a particular medium (audio, video, etc.).

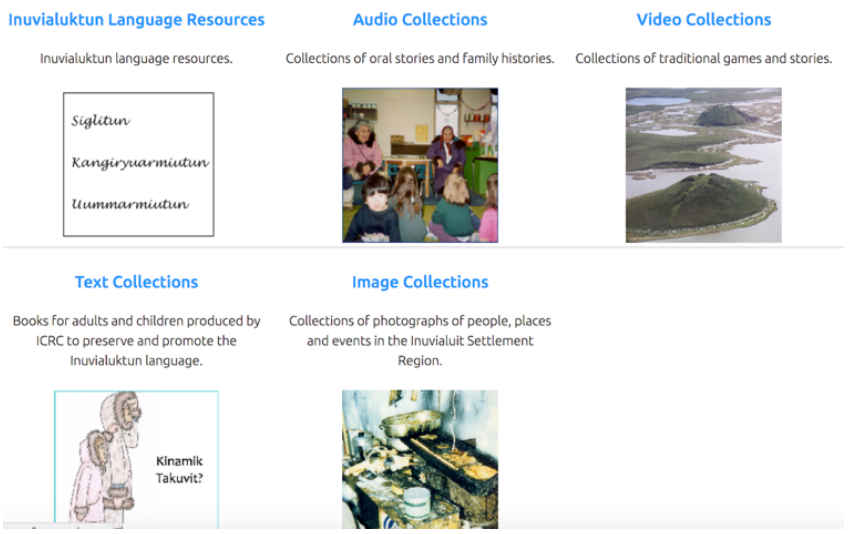

Figure 2. Browse by Collection page

The initial Browse by Collection page had no visuals to accompany the text. Community members we spoke to preferred a more visual design and so a first revision was to incorporate icons in addition to text.

Although this is the current high-level organization of the Library, Inuvialuit knowledge organization practices have taught us to think about different approaches to organizing digital content. In our community field trips and visiting schools in Ulukhaktok we found that teachers make particularly creative use of seasons as organizational schemes on the walls of classrooms to categorize images of people, places and animals to facilitate learning. This is one of the evident examples of how seasons could be used to tag digital objects in the library to allow browsing and filtering content based on seasons.

A third alternative or additional option for a high-level organizational structure is geographic. The Library currently includes prototype mapping functionality, which uses the geographic subject of a resource to locate it on a map (see Figure 3). This allows you to locate a single item at a time on a map. However, the community has expressed strong interest in being able to select a place or area on the map and see all associated items. 


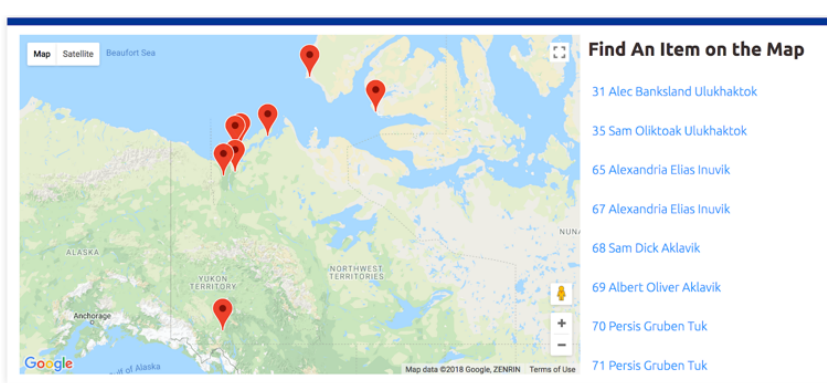

Figure 3. Locate an Item on the Map

\section{Language and Dialect}

One of the key decisions in organizing digital content in the Library was to place particular emphasis on the Inuvialuktun language and its three dialects, namely Kangiryuarmiutun, Siglitun, and Uummarmiutun, as a key knowledge organization and information architecture design. The purpose was to provide easy and meaningful access to the language learning and language revitalization resources available in the $\mathrm{Li}$ brary. Although many resources in the Library were designed specifically for language learning, any that have a linguistic trait - audio, video, texts - contribute to language learning and revitalization. For this reason, it was very clear from our conversations with community that language and dialect were essential pieces of the metadata framework. In addition, because many of the stories captured in the language booklets originated from one area of the region and were in a particular dialect, the ability to capture original dialect was added to the framework. Lastly, each dialect is most closely associated with specific communities within the ISR. For this reason, ICC staff suggested that language resources in a particular dialect have the associated communities listed as geographic subject in addition to place of publication or the topical place.

\section{Geographic Names}

Place is extremely important to individuals and communities within the ISR and therefore capturing geographic aspects of resources is crucial. The Inuvialuit, like many Indigenous communities, had most of their traditional names for important places replaced by names reflective of the colonial enterprise. However, these names have never been forgotten, and are beginning to be reclaimed by the community. Community members have indicated the importance of using these traditional or local place names for resources in the $\mathrm{Li}$ brary. They have indicated, however, that the colonial name should also be used. This is a part of their history that must be recognized, many have noted. In addition, many Inuvialuit and non-Inuvialuit only know the places by those colonial names. Examples include Akłarvik (Aklavik), Inuuvik / Iñuuvik (Inuvik), Utqaluk (Baillie Island).

\section{Contributors and Roles}

The importance of noting all contributors to a resource, and the role they played, was expressed as being extremely important. This recognizes and honours the knowledge and resources of these individuals and is crucial to respectful representation. Language resources, for example, capture the names and roles of translators, storytellers, illustrators, and so on. Videos capturing drum dancing ceremonies capture not only those who recorded or edited or directed the program, but just as importantly the names of the drummers and dancers. With image resources what is most important to record is not necessarily who took the photograph, but who is depicted.

\section{Subjects}

The topic of the resources is considered to be extremely important for browsing and searching. To enable subject access, the Library incorporates several existing knowledge organization systems, as well as a locally developed term list. A decision was made to look to Canadian Subject Headings (CSH), Indigenous and Northern Affairs Canada Subject Thesaurus (IST), Faceted Application of Subject Terminology (FAST), and Thesaurus for Graphic Materials (TGM). For ease of application of terms and to improve usability of the Digital Library, we have been flexible in application of these vocabularies. For example, we have been moving away from complex pre-coordinated strings to a more faceted approach, so from Folk songs, Inuvialuit--Canada--Northwest Territories--Inuvialuit Settlement Region (ISR) to separate entries for Folk songs, Inuvialuit, and each of the geographic subdivisions. As well, we have been incorporating more specific terms, such as Inuvialuit rather than Inuit.

Of course, these vocabularies are very often not adequate or appropriate for describing resources in the Library. Therefore, we have been working with ICC staff and community partners on a local term list to supplement and/or replace terms from these existing vocabularies. This term list includes names of people (e.g., Nuligak (Cockney, Bob), Koiksak (Quiqsaq, Raddi)) and places (e.g., Tuktuuyaqtuuq / Tuktuuraqtuuq (Tuktoyaktuk), Qaaqturvik (Kaktovik)), both traditional and westernized, as well as organizations (e.g., East Three Reelers, Inu-Yupiaq Dancers) and topics (e.g., Blanket toss, Ulu). It also captures alternative spellings and dialect variations. This is a living document that continues to evolve as we work collaboratively on the Library.

\section{CONCLUSION}

Developing knowledge organization systems for Indigenous cultural heritage digital libraries and archives requires multidisciplinary theoretical and methodological frameworks that take into account the cultural nuances of aboriginal knowledge creation, sharing and dissemination. In this context, community engagement provides a foundation not only for research design and participation activities, but also serves as a holistic framework that determines what data gathering, analysis, dissemination and sharing methods and techniques are appropriate. Only through close community engagement can a knowledge organization system remain culturally relevant and sustainable.

\section{REFERENCES}

Balanoff, H., Kudlak, E., Kaodloak, A., Chambers, C. (2006). 'This is the way we were told ...': multiple literacies in Ulukhaktok, Northwest Territories. In B. Collignon, M. Therrien (Eds.), INALCO 2009, proceedings of the 15th Inuit studies conference, orality Paris, 2006 (pp. 1-16).

Baydala, A., Placsko, C., Hampton, M., Bourassa, C., McKay-McNabb, K. (2006). A narrative of research with, by, and for Aboriginal peoples. Pimatisiwin 4(1), 47-65. 
Bushnell, J. (2009). "I can think of a lot of stories." Shared knowledges, indigenous methodology and purposeful conversations with sixteen native women in Seattle. Retrieved from ProQuest Digital Dissertations.

Chilisa, B. (2012). Indigenous research methodologies. Thousand Oaks, CA: SAGE Publications.

Digital Library North. (2017). Retrieved from https://sites.google.com/ualberta.ca/dln/home

Hart, M. A. (2010). Indigenous worldviews, knowledge, and research: the development of an Indigenous research paradigm. Journal of Indigenous Voices in Social Work 1(1), $1-16$.

Hollowell, J., \& Nicholas, G. (2009). Using ethnographic methods to articulate community-based conceptions of cultural heritage management. Public Archaeology 8(2/3), 141-160.

Inuvialuit Cultural Centre. (2017). Retrieved from $\mathrm{http} / / / \mathrm{www}$.irc.inuvialuit.com/service/inuvialuit-culturalresource-centre

Inuvialuit Regional Corporation. (2017). Retrieved from http://www.irc.inuvialuit.com/

Kovach, M. (2005). Emerging from the margins: Indigenous methodologies. In L. Brown, S. Strega (Eds.), Research as resistance: critical, Indigenous, \& anti-oppressive approaches (pp. 19-36). Toronto, ON: Canadian Scholars' Press.

Kovach, M. (2010). Conversational method in Indigenous research. First Peoples Child \& Family Review 5(1), 40-48.

Lavallée, L. F. (2009). Practical application of an Indigenous research framework and two qualitative Indigenous research methods: sharing circles and Anishnaabe symbolbased reflection. International Journal of Qualitative Methods 8(1), 21-40.

Lincoln, Y., Lynham, S., Guba, E. (2011). Paradigmatic controversies, contradictions, and emerging confluences, revisited. In N. K. Denzin \& Y. S. Lincoln (Eds.), The Sage handbook of qualitative research (4th ed.). Thousand Oaks, CA: Sage Publications.

Shiri, A. \& Rathi, D. (2015) Digital Library North: Development of Model Digital Library Platform for Northern Canada. Open Shelf. February 15, 2015. Retrieved from http://www.open-shelf.ca/digital-library-north-project/

Walts, Nathan. (2011). Native American Indian Tribal College and University Students: A Qualitative Study of the Digital Divide (Ph.D. dissertation, University of Phoenix, 2011).

Wilson, S. (2008). Research is ceremony: Indigenous research methods. Black Point, NS: Fernwood Publishing. 